\title{
Note on Constant-Deciation Prisms
}

This content has been downloaded from IOPscience. Please scroll down to see the full text. 1906 Proc. Phys. Soc. London 20105

(http://iopscience.iop.org/1478-7814/20/1/306)

View the table of contents for this issue, or go to the journal homepage for more

Download details:

IP Address: 139.184.14.159

This content was downloaded on 05/09/2015 at 13:31

Please note that terms and conditions apply. 
Then if

$$
\begin{aligned}
& d=\text { distance apart of pliates, } \\
& N=\text { frequency, } \\
& V=\text { voltage between plates, }
\end{aligned}
$$

we have

$$
\mathrm{V}=k d \times \mathrm{N} . \quad \text {. . . . . . . }
$$

An instance of this application has been given already Another may be added :-

The difference of potential yielded by a Wimshurst machine was measured by charging a Leyden jar, the outer coating, being connected to one pole, the innor to the other pole, the poles being kept well apart. The jar was connected with the pair of parallel plates, which were at a distance of $10.5 \mathrm{cms}$. apart. The frequency of the neelle in the field between them was 2.04 per sec. The needle used hal a constant (reduced to $d=1 \mathrm{~cm}$.) of 1300 volts. Applying formula III, we have

$$
\begin{aligned}
\mathrm{V} & =1300 \times 10 \cdot 5 \times 2.04 \\
& =27800 \text { volts }
\end{aligned}
$$

The machine, it may le added, was working badly, giving, a spark between balls of 2 cms. and 5 cms. diameter lespectively, Leyden jaxs being in, of something less than $1 \mathrm{~cm}$. length.

These experiments were mate in the laboratories of the Birkbeck College. I would record my thanks to the Principal for facilities for carrying them ont.

\section{Note on Constant-J leciation l'risins. \\ By '. H. Beakfolliy.*}

IT appears that any prism of three faces can be made to give a spectrum in which the light, that oceupies the centre of the field of riew of the telcscope at any moment, has undergone passage through the two refracting surfaces of the prism in such a way that its original angle of incidence is equal to its tinul angle of emergenee. This condition, which ir the ordinary employmerit of the prism is associated with minimum deviation, must be describod as isogonal passage, the property which has the minimun value being not the

* Read November 10 , 1900.

rol. Xx. 
deviation, but the rate of passige across the field of riew for a given motion of the jrimm, to which alone in these instruments motion hits to be given to bring different parts of the suectrum into the field, the telescope and collimator both remaining fixed. If any triangle having the angles $\alpha, \beta, \gamma$ is adopted as the shape of a prism, the telescope must be set to make me of these angles, say $\gamma$, with the line of the collimator. J'hon the prism being placed in the region between them, a position can be found so that any ray selected will be refracted through one of the sides containing the angle $\gamma$, reflected at the side opposite $\gamma$, and finally refracted through the remaining side containing $\gamma$. On emergence it will be parallel to the telescope, and its passage through the refracting faces will be isogomal. The prism will affect the light to the same degree as one used in the ordinary way, of refrating angle $\beta-\alpha$, would do. The sine of the angle of original incidence is equal to $\mu . \sin (\beta-\alpha) / 2$ for every ray occupying the centre of the field of riew.

If the prisin is turned over but the same angle $y$ employed, tho telescope will remain unaltered bat the spectrum will rum in an opposite direction to the first. If $n$ similar prisms are piled one upon another, the diamcter of the telescope and collimator being large enough to embrace them all, n different parts of the spectrum may be brought into coincidence at the centre of the field of view. Thus such prisms affurd an axcellent mode of mixing colours. Mr. Blakesley showed the case of two prisms in which the spectra ran in clifferent directions. The top prism was slighlity tilted by the insertion of a small piece of silver paper between the prisms. Byy this means one of the spectra was shifted upward by a smanl amount, and one could seo in the telescope a band, at top and bottom, of the component colours, and in the centre a bund of the resulting colours. It was suggested that spectroscopes on this plan could be advantageously employed in mensuring the motion on the line of sight of heavenly bodies, as a line brought into coincilence with itself for a terrestrial sonrce in the two spectra would, in tise case of such motion, split "u into two moving different ways in the field of view. It was also explained how such jurisms could be placed in trains for increased dispersion. 